\title{
Place your bets: psychophysiological correlates of decision-making under risk
}

\author{
Bettina Studer • Luke Clark
}

Published online: 6 March 2011

(C) The Author(s) 2011. This article is published with open access at Springerlink.com

\begin{abstract}
Emotions and their psychophysiological correlates are thought to play an important role in decisionmaking under risk. We used a novel gambling task to measure psychophysiological responses during selection of explicitly presented risky options and feedback processing. Active-choice trials, in which the participant had to select the size of bet, were compared to fixed-bet, no-choice trials. We further tested how the chances of winning and bet size affected choice behavior and psychophysiological arousal. Individual differences in impulsive and risk-taking traits were assessed. The behavioral results showed sensitivity to the choice requirement and to the chances of winning: Participants were faster to make a response on no-choice trials and when the chances of winning were high. In active-choice trials, electrodermal activity (EDA) increased with bet size during both selection and processing of losses. Cardiac responses were sensitive to choice uncertainty: Stronger selection-related heart rate (HR) decelerations were observed in trials with lower chances of winning, particularly on active-choice trials. Finally, betting behavior and psychophysiological responsiveness were moderately correlated with self-reported impulsivity-related traits. In conclusion, we demonstrate that psychophysiological arousal covaries with risk-sensitive decision-making outside of a learning context. Our results further highlight the differential sensitivities of EDA and HR to psychological features of the decision scenario.
\end{abstract}

Keywords Decision-making · Risk · Psychophysiology · Emotion $\cdot$ Personality

\section{B. Studer $(\bowtie) \cdot$ L. Clark}

Department of Experimental Psychology,

University of Cambridge,

CB2 3EB Cambridge, England, UK

e-mail: bs410@cam.ac.uk
Decision-making is an important aspect of everyday life and often involves the assessment of risk. Economic models predict that, when faced with a risky decision, humans integrate information about the magnitude of potential wins and losses, as well as the probability of those outcomes occurring, in order to select the option with the highest subjective expected value. Decision-making under risk has been studied with a wide range of laboratory gambling tasks in which the participant risks a stake on the uncertain prospect of receiving a monetary reward (for reviews, see Brand, Labudda, \& Markowitsch, 2006; Platt \& Huettel, 2008; Vorhold, 2008). A common finding from this research has been that economic models underestimate the role of emotions in guiding human choice (for reviews, see Coricelli, Dolan, \& Sirigu, 2007; Kenning \& Plassmann, 2005; Lee, 2006; Platt \& Huettel, 2008), and emotional inputs have been conceptualized within a number of influential theories (e.g., Damasio, 1994; Damasio, Everitt, \& Bishop, 1996; Loewenstein, Weber, Hsee, \& Welch, 2001; Slovic, Finucane, Peters, \& MacGregor, 2007).

Emotions comprise both subjective and physiological (somatic/autonomic) components (see, e.g., Dolan, 2002; Lang \& Davis, 2006), and thus psychophysiological responses during task performance provide a window into emotional processing. A range of experimental data show that physiological signals (e.g., facial expressions, body movements) modulate choice behavior and judgment (Barrett \& Lindquist, 2008; Niedenthal, 2007; Niedenthal, Barsalou, Winkielman, Krauth-Gruber, \& Ric, 2005). Most importantly, previous research using the Iowa Gambling Task has shown that electrodermal activity (EDA) during choice covaries with decision riskiness (e.g., Bechara, Damasio, Damasio, \& Lee, 1999; Bechara, Damasio, Tranel, \& Damasio 1997; Tchanturia et al., 2007; Tomb, Hauser, Deldin, \& Caramazza, 2002) and that participants 
with a stronger physiological differentiation of good and bad options during card selection achieved better task performance (Carter \& Pasqualini, 2004; Crone, Somsen, Van Beek, \& Van der Molena, 2004; Guillaume et al., 2009). However, the Iowa Gambling Task assesses decision-making under ambiguity rather than under explicit risk, and it is unclear whether psychophysiological signals reflect the riskiness of choice options even when learning is not required-that is to say, under explicit risk. In the present study, we used a novel decision-making task in which the risks of decision options were presented explicitly.

In the present study, we investigated the psychophysiological correlates of risk-sensitive decision-making in a novel gambling task, the Roulette Betting Task. In half of the trials, participants were asked to actively select the size of the bet (active-choice trials), and in the other half of the trials, the bet size was fixed (no-choice trials). Across trials, the chances of winning and the size of the bet were also manipulated. To assess psychophysiological arousal, both EDA and cardiac responses were measured and then analyzed separately during the selection phase and the presentation of feedback (i.e., wins and losses). Previous research on heart rate (HR) responses to emotional stimuli has identified two distinct markers (for reviews, see Bradley, 2000; Hodes, Cook, \& Lang, 1985): an initial HR deceleration, interpreted as a sign of attentional orienting and parasympathetic activity (e.g., Bradley, 2009; Bradley, Codispoti, Cuthbert, \& Lang, 2001; Graham \& Clifton, 1966; Osumi \& Ohira, 2009), and a later HR acceleration, an indicator of emotional arousal and sympathetic activity (Bradley \& Lang, 2007; Cook, Hawk, Davis, \& Stevenson, 1991). Previous work has furthermore shown that HR decelerations are sensitive to response monitoring (Hajcak, McDonald, \& Simons, 2004; Somsen, Van der Molen, Jennings, \& van Beek, 2000) and to violations of the expectancy of outcomes (Crone et al., 2003). Following this research, we decomposed the HR time course into deceleration and acceleration components.

The main goal of this study was to examine how psychophysiological arousal and risk-taking behavior (i.e., the bet size, decision latency) are differentially affected by (a) the requirement to make an active choice, (b) the choice uncertainty (the chances of winning), and (c) the bet size (the magnitude of potential wins/losses).

\section{Requirement for active choice}

The role of active choice is highlighted in real gambling behavior by the phenomenon of "illusory control" (Langer, 1975). In games of pure chance, gamblers will place higher bets when given the opportunity to make a choice or make a motor response, relative to situations in which they do not have such agency (Davis, Sundahl, \& Lesbo, 2000; Henslin, 1967; Ladouceur \& Mayrand, 1987; Langer, 1975). Active choice also influences the processing of outcomes. Neuroimaging studies have shown that the activation of the mesolimbic system in response to monetary rewards is modulated by the requirement for an active response (O’Doherty et al., 2004; Tricomi, Delgado, \& Fiez, 2004; Walton, Croxson, Behrens, Kennerley, \& Rushworth, 2007; Zink, Pagnoni, Martin-Skurski, Chappelow, \& Berns, 2004), and on risky decision-making tasks, feedback-related brain activity varied according to whether the win or loss occurred as a result of choice by the participant or by the computer (Coricelli et al., 2005; Rao, Korczykowski, Pluta, Hoang, \& Detre, 2008). Ratings of the pleasantness of wins (Clark, Lawrence, Astley-Jones, \& Gray, 2009) and feedback-related HR responses (Coricelli et al., 2005; Crone, Bunge, de Klerk, \& van der Molen, 2005) are also higher in active-choice conditions. Few studies have assessed agency effects upon the selection of options that explicitly vary in riskiness. Rao et al. (2008) showed that the mesolimbic reward system was differentially activated during the voluntary selection of a risky option, as compared to involuntary, passive risk-taking. On the basis of these results, we predicted that psychophysiological reactivity (EDA, HR deceleration, and HR acceleration) during the selection phase (Hypothesis 1A) and the feedback phase (Hypothesis 1B) would be stronger on trials in which participants had actively chosen a bet, relative to fixed-bet trials.

\section{Chances of winning and bet size}

Our design allowed the impact of two further decision parameters to be evaluated: the chances of winning and the bet size. Economic studies of decision-making behavior have indicated that both of these factors play roles in the valuation of risky gambles (Bossaerts \& Plott, 2004; Holt \& Laury, 2002), and previous neuroimaging studies confirmed that during selection of risky options, the probability and magnitude of potential rewards modulate distinct signals in the brain (Critchley, Mathias, \& Dolan 2001; Huettel, Song, \& McCarthy, 2005; Huettel, Stowe, Gordon, Warner, \& Platt, 2006; Preuschoff, Bossaerts, \& Quartz, 2006; Preuschoff, Quartz, \& Bossaerts, 2008; Smith et al., 2009; Tobler, Christopoulos, O’Doherty, Dolan, \& Schultz, 2009; Xue et al., 2009). The neural substrates implicated (insula, anterior cingulate cortex) overlap with regions implicated in the representation of physiological states (Craig, 2009, 2010; Craig, Chen, Bandy, \& Reiman, 2000; Critchley, 2005; Critchley, Elliott, Mathias, \& Dolan, 2000; Critchley et al., 2001; Critchley et al., 2003; Gianaros, Van der Veen, 
\& Jennings, 2004; Ohira et al., 2010; Thayer \& Lane, 2009). There is also evidence that choice itself is differentially affected by the probability and magnitude of potential rewards. For example, participants put a stronger emphasis on the probability of outcomes when asked to judge the attractiveness of gambles, whereas the magnitude of potential wins has a stronger influence when participants are asked to price risky financial gambles (Lichtenstein \& Slovic, 1971; Slovic et al., 2007; Slovic \& Lichtenstein, 1968). A previous study by Crone et al. (2004) indicated that different psychophysiological measurements during selection might signal different aspects of the riskiness of choices on the Iowa Gambling Task: EDA during card selection was found to reflect the overall riskiness of the choice, whereas HR decelerations seem to be sensitive to the frequency rather than the magnitude of punishment. Research on the psychophysiological responses to wins and losses in gambling tasks has furthermore shown that feedback-related EDA is modulated by the valence (Bechara et al., 1999; Crone et al., 2004; Dixon, Harrigan, Sandhu, Collins, \& Fugelsang, 2010; Liao et al., 2009; Starcke, Tuschen-Caffier, Markowitsch, \& Brand, 2009; Tchanturia et al., 2007; Wilkes, Gonsalvez, \& Blaszczynski, 2010) and the magnitude (Crone et al., 2004; Wilkes et al., 2010) of outcomes. In contrast, feedback-related HR decelerations reflect the frequency of losses (Crone et al., 2004) and seem to be modulated by valence only in tasks where the outcomes should be used to adjust future selection (Crone et al., 2005; Crone et al., 2004; Miu, Heilman, \& Houser, 2008; Somsen et al., 2000; but see also Van der Veen, Van der Molen, Crone, \& Jennings, 2004).

On the basis of these findings, we predicted that the chances of winning would modulate HR decelerations during the selection of explicitly risky decisions (Hypothesis 2) and in response to feedback (Hypothesis 3), whereas the size of bets would influence EDA and HR accelerations during the selection phase (Hypothesis 4) and the feedback phase (Hypothesis 5). In addition, we expected that feedback-related EDA and HR accelerations would reflect the valence of outcomes (Hypothesis 6).

\section{Individual differences in risk-taking behavior}

Other previous research has highlighted important sources of heterogeneity in risk-taking behavior. In healthy participants, high trait impulsivity was associated with deficits in decision-making and reward-learning performance (Franken, van Strien, Nijs, \& Muris, 2008; Sweitzer, Allen, \& Kaut, 2008). Elevated levels of impulsivity and novelty seeking have also been observed in clinical conditions associated with risky decision-making, namely pathological gambling and drug addiction (for a review, see Verdejo-
García, Lawrence, \& Clark, 2008). Functional imaging studies have indicated a positive correlation between impulsivity-related traits and neural activity in the ventral striatum and orbitofrontal cortex, during reward anticipation (Hahn et al., 2009), and activity in nucleus accumbens and mesofrontal cortex, in response to reward feedback (Bjork, Smith, \& Hommer, 2008). Thus, individual differences in decision-making and its neural correlates can be explained partly by differences in trait personality. No studies, however, have investigated whether these relationships extend to psychophysiological responses during decision-making. In the present study, we assessed trait personality (Barratt Impulsivity Scale, Sensation-Seeking Scale, and BIS/BAS) and everyday risk-taking preferences (DOSPERT), and conducted exploratory data analysis to investigate whether impulsivity-related personality traits modulate behavioral and psychophysiological responses during risky decision-making in our sample of healthy participants.

\section{Method}

\section{Participants}

A total of 30 right-handed healthy university students took part in this study ( 20 females, 10 males; mean age $=23$ years, $S D=3.18$ ). Volunteers were told that their reimbursement for participation depended on their final score in the task and would range between $£ 5$ and $£ 10$ (in reality, all participants received between $£ 9$ and £10). The study was approved by the local ethics committee and was conducted in accordance with the Declaration of Helsinki. All participants gave written informed consent.

\section{Procedure}

All participants attended a single testing session at the University of Cambridge. They completed several personality and risk-taking questionnaires: the Barratt Impulsivity Scale (Version 11; Patton, Stanford, \& Barratt, 1995), the BIS/BAS (Carver \& White, 1994), the Domain-Specific Risk-Taking (DOSPERT) Scale (Blais \& Weber, 2006), and the Zuckerman Sensation Seeking Scale (SSS) (Zuckerman, Eysenck, \& Eysenck, 1978). The Barratt Impulsivity Scale contains 30 items used to evaluate self-control and forward planning. The BIS/BAS was developed to assess Gray's hypothesized behavioral inhibition system and behavioral activation systems, which are thought to guide motivational behavior. The DOSPERT assesses risk-taking (the likelihood of engaging in an activity) and risk-perception (the judged riskiness of an activity) in five domains (ethical, financial, health/safety, social, and recreational decisions). 
The Zuckerman Sensation Seeking Scale assesses boredom susceptibility, thrill and adventure seeking, experience seeking, and disinhibition.

\section{Task}

Participants were administered the Roulette Betting Task, a novel computerized task that assesses risk-sensitive decision-making. The task was programmed in Visual Basic 2008 (Microsoft Corp., Redmond, WA, USA) and administered on a laptop PC with keyboard control. Participants completed a total of 75 trials on the task, divided into five blocks of 15 trials each. Each trial consisted of three phases: selection, anticipation, and feedback (see Fig. 1). First, a wheel with ten equally sized red and blue segments was presented, along with three bets. The ratio of blue (winning) and red (losing) segments varied across trials, reflecting the chances of winning $(60 \%$, $70 \%$, or $80 \%$ ). The presentation of the wheel initiated the selection phase: Participants were asked to choose one of the three presented bet boxes by pressing a corresponding key on a keyboard. Two trial types were contrasted: activechoice trials, in which the participants were required to select a bet $(10,50$, or 90 points), and no-choice trials (matched for monetary gain), in which all three bets boxes contained identical amounts. Once a bet had been selected, the wheel was spun for an anticipation period. A relatively long anticipation period, varying between 4 and $6 \mathrm{~s}$, was used in order to obtain temporal segregation of selectionand feedback-related psychophysiological responses. The wheel stopped on one of the ten segments, initiating the feedback period. If the wheel stopped on a blue segment, the chosen amount of points was won, and the outcome message "YOU WON [XX] POINTS" was presented. If the wheel stopped on red, the selected amount of points was lost, and the message "YOU LOST [XX] POINTS" appeared. At the end of each trial, a fixation cross was displayed for a variable intertrial interval (between 8 and $12 \mathrm{~s}$ ). In order to minimize the influence of accumulated score upon betting on a trial-by-trial basis, the current point score was only presented to participants at the end of each block.

Data acquisition

A Biopac system (MP150, recording at 1,000 samples per second; Biopac Systems, Goleta, CA, USA) with two amplifiers (ECG100C module and GSR100C module) was used to measure EDA and the electrocardiogram (ECG) throughout the task. Electrodes were attached prior to beginning the task, and at least $2 \mathrm{~min}$ of resting-state activity were recorded in order to allow participants to adapt to the recording equipment, and to allow EDA levels to stabilize (see Fowles et al., 1981). EDA was measured using two grounded $\mathrm{Ag}-\mathrm{AgCl}$ electrodes attached to the distal phalange of the index and middle fingers of the nondominant hand. Isotonic paste (BIOPAC Gel 101) was used as the electrolyte. A low-pass filter of $1.0 \mathrm{~Hz}$ and a DC high-pass filter were applied to the EDA recording. HR was recorded using disposable $\mathrm{Ag}-\mathrm{AgCl} \mathrm{ECG}$ electrodes (Vermed EL503 patches) secured to the right dorsal forearm and left ankle. The ECG recording was high-pass filtered at $0.05 \mathrm{~Hz}$. AcqKnowledge Software (Version 3.9.0; Biopac Systems) was used to record and event-mark the psychophysiological data. The EDA signal was transformed into units of microsiemens, and for the cardiac data, interbeat intervals were obtained from deviations between the ECG $\mathrm{R}$-waves and were transformed online into beats per minute (bpm) - that is, HR.

\section{Data analysis}

Behavioral responses were assessed using the following measurements: (a) decision latency, or the time between wheel onset and the selection of a bet option; (b) average bet amount, in active-choice trials; and (c) risk adjustment in active-choice trials, or the degree to which participants adjusted their bets to the varying chances of winning, formalized as the average change in bet size (in $60 \%$ - and $70 \%$-trials) as a percentage of the bet on $80 \%$-trials.
Fig. 1 Task design. Each trial consisted of three phases: (1) selection, in which the participant chose one of the bet options (here, an active-choice trial is depicted); (2) anticipation, in which the wheel was spun; and (3) feedback. The variable intertrial interval is not shown on this graph

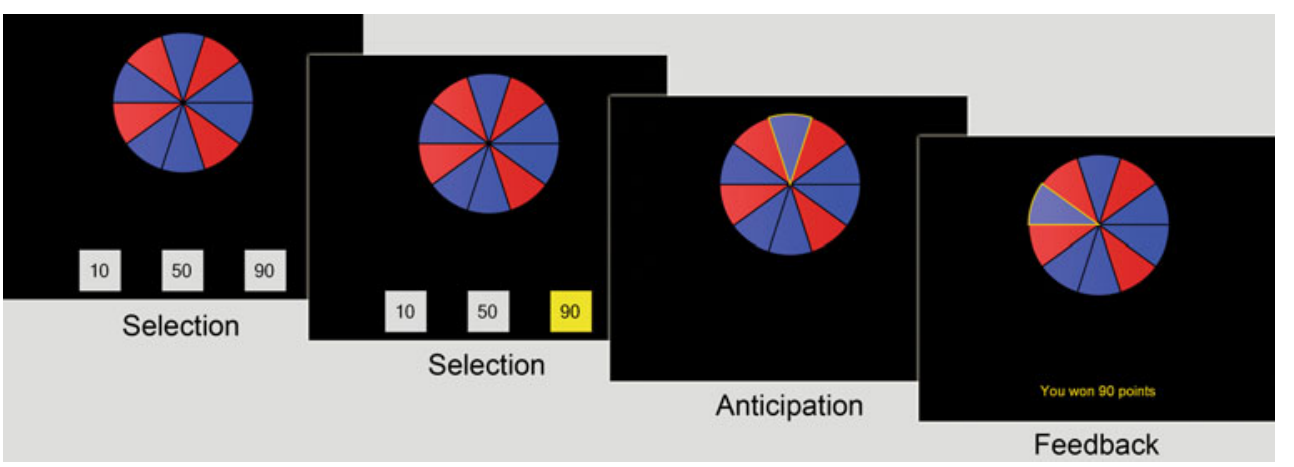


Psychophysiological responses were analyzed separately for the selection phase and the feedback phase. Changes from baseline scores were calculated, using a 1-s baseline interval immediately preceding either the selection or the feedback phase. Given that EDA responses are uniphasic, typically peaking between 2 and $6 \mathrm{~s}$ poststimulus (Dawson, Schell, \& Filion, 2007), we calculated feedback-related EDA as the maximum value during the interval $2-6 \mathrm{~s}$ after the onset of feedback minus the feedback baseline. For selection-related EDA, we allowed a slightly longer time window of 2-7 s after trial onset (minus baseline), given that choice-related arousal is unlikely to occur in immediate response to the trial onset. Unlike EDA, the cardiac response to motivational stimuli is typically biphasic (for reviews, see Bradley, 2000, 2009; Bradley \& Lang, 2007; Graham \& Clifton, 1966; Hodes et al., 1985), and we therefore extracted the initial HR deceleration component and the subsequent HR acceleration component separately (cf. Bradley et al., 2001; Osumi \& Ohira, 2009). The selection-related HR deceleration peak was defined as the minimum HR value $0-3 \mathrm{~s}$ after onset of the wheel minus the selection baseline, and the selection-related HR acceleration peak was defined as the maximum value $2-6 \mathrm{~s}$ after the onset of the wheel minus the selection baseline (see Fig. 2). Feedback-related summary measures were calculated in the same manner.

Of the participants, 6 were excluded from the EDA analysis due to technical problems, and 2 were excluded from the HR analyses: 1 was excluded due to a technical problem during data acquisition, and the other was

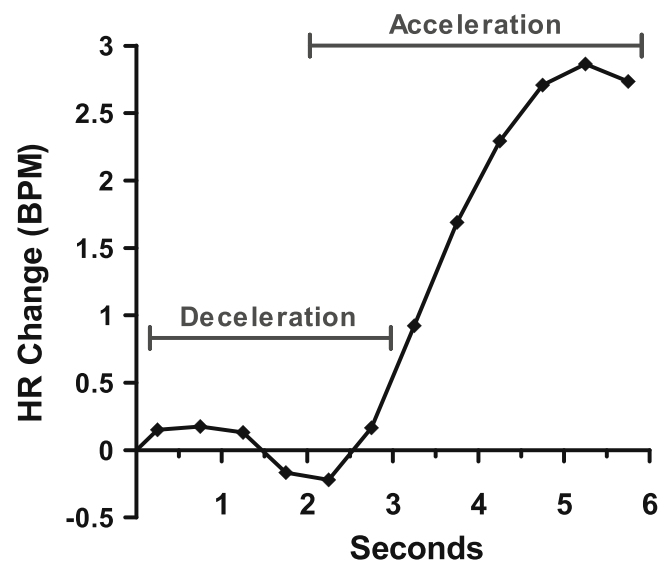

Fig. 2 The cardiovascular time course at selection onset. Selectionrelated change in heart rate (HR, in beats per minute) was averaged across 0.5 -s bins, for all trials and all participants, to illustrate the prototypical biphasic function. We extracted the HR deceleration $(0-$ $3 \mathrm{~s}$ after wheel presentation) and the HR acceleration (2-6s) using the peak values (i.e., deceleration minimum and acceleration maximum values, rather than mean values) within those epochs. Thus, the peak scores used in the analysis were stronger than the responses depicted here excluded due to extreme values (more than $2 S D$ s from sample mean).

Statistical analysis of the psychophysiological and behavioral data was conducted in SPSS (Version 15.0; SPSS Inc., Chicago, IL, USA). The effects of choice uncertainty and bet size were investigated in separate analyses. To assess the impact of choice uncertainty, a repeated measures ANOVA with the Chances of Winning $(60 \%, 70 \%$, or $80 \%)$ and Choice Condition (active-choice vs. no-choice) as factors was conducted on decision times and the selection-related psychophysiological measurements (EDA, HR deceleration, and HR acceleration). The effects of bet size were assessed using repeated measures ANOVA with Choice Condition (active-choice vs. nochoice) and Bet Size as factors. In active-choice trials, a number of participants did not select all available options throughout the task. For the investigation of bet size effects, we therefore collapsed the 10- and 50-point bets together in comparison against the high bets (90 points). To prevent any effects of heteroscedasticity, Greenhouse-Geisser corrections were applied to ANOVAs when sphericity could not be assumed (Mauchly's sphericity test $<.05$ ). Follow-up comparisons were then conducted. All statistical tests are reported two-tailed, and alpha was set at .05 .

An exploratory analysis was conducted to investigate links between individual differences in trait personality and behavioral and psychophysiological responses. Nonparametric correlations were conducted, and 95\% confidence intervals (CIs) were calculated as an effect size estimator for the correlation coefficients. The following personality measurements were used for this analysis: impulsivity (Barratt total score), behavioral inhibition (BIS total), behavioral activation (BAS total), sensation seeking (SSS total), financial risk-taking (DOSPERT), and financial riskperception (DOSPERT). Three psychophysiological measurements were calculated: (1) the difference between selection-related arousal on active-choice versus no-choice trials; (2) the difference between selection-related arousal to active choice of a high bet versus active choice of a low bet; and (3) the difference between feedback-related arousal to wins versus losses. In separate analyses, we then calculated the correlations between the personality scores and (a) behavioral responses (average bet and average riskadjustment on choice trials), (b) selection-related EDA measurements, (c) selection-related HR measurements, (d) feedback-related EDA measurements, and (e) feedbackrelated HR measurements.

\section{Results}

Behavioral responses were sensitive to both the chances of winning and the requirement for active choice: A 3 
(chances of winning) $\times 2$ (choice condition) repeated measures ANOVA on the decision latencies revealed a significant Chances of Winning $\mathrm{x}$ Choice Condition interaction $\left[F(2,58)=9.427, p<.001, \eta_{p}^{2}=.25\right]$, as well as significant main effects of chances of winning $[F(2,58)=$ $\left.53.80, p<.001, \eta_{p}^{2}=.65\right]$ and choice condition $[F(1,29)=$ $\left.47.21, p<.001, \eta_{p}^{2}=.62\right]$. Participants were faster to select their bet on no-choice than on active-choice trials $(p<.001)$. On both active-choice and no-choice trials, participants were faster to select a bet on the $80 \%$ trials than on the $70 \%$ trials, and faster on the $70 \%$ trials than on the $60 \%$ trials $(p \mathrm{~s}<.001)$. The significant interaction was explained by the differences in decision latencies between $60 \%$, $70 \%$, and $80 \%$ trials (i.e., the slopes of the lines of best fit) being higher on active-choice trials than on no-choice trials $(p<.001)$ (see Fig. 3a).

In addition, participants adjusted their bets to the winning chances on active-choice trials: A significant main effect of chances of winning was found $[F(1.5,43.1)=$ $\left.67.96, p<.001, \eta_{p}^{2}=.70\right]$, with higher bets chosen on the $80 \%$ than on the $70 \%$ trials, and higher bets likewise on the $70 \%$ than on the $60 \%$ trials $(p s<.001)$ (see Fig. $3 b$ ).

\section{Effects of active choice and chances of winning}

\section{Selection-related psychophysiological responses}

The requirement for active choice modulated selectionrelated EDA. A 3 (chances of winning) x 2 (choice condition) ANOVA $(n=24)$ revealed a significant main effect of choice condition $[F(1,23)=4.70, p<.05$, $\left.\eta_{p}^{2}=.17\right]$, with stronger selection-related EDA on activechoice than on no-choice trials. There was no significant main effect of chances of winning $[F(2,46)=1.56]$, nor any Chances of Winning $x$ Choice Condition interaction $[F(1.6,46)=0.95]$.

Selection-related HR decelerations were also affected by the requirement of active choice, and additionally were sensitive to the chances of winning. A 3 (chances of winning) x 2 (choice condition) ANOVA $(n=28)$ revealed a significant main effect of chances of winning $[F(2,54)=$ 4.32, $\left.p<.05, \eta_{p}^{2}=.14\right]$ and a marginally significant effect of choice condition $\left[F(1,27)=3.41, p=.08, \eta_{p}^{2}=.11\right]$, but no significant Chances of Winning $\mathrm{x}$ Choice Condition interaction $[F(2,54)=0.63]$. Post-hoc analyses showed a significant main effect of chances of winning on activechoice trials $\left[F(2,54)=3.99, p<.05, \eta_{p}^{2}=.13\right]$, with stronger HR decelerations on $60 \%$ trials than on either $70 \%$ or $80 \%$ trials $(p \mathrm{~s}<.01)$, but no effect on no-choice trials $[F(2,54)=1.66]$ (see Fig. 4).

HR accelerations during selection, on the other hand, were not systematically affected by either the requirement for active choice or the chances of winning. A 3 (chances of winning) $\times 2$ (choice condition) ANOVA found no significant main effects [chances of winning, $F(2,54)=$ 2.50; choice condition, $F(1,27)=1.78]$ nor a significant Chances of Winning $\mathrm{x}$ Choice Condition interaction $[F(2$, $54)=1.55]$.

Feedback-related psychophysiological responses

The requirement for active choice modulated feedbackrelated EDA. A 3 (chances of winning) x 2 (choice condition) $\times 2$ (outcome) ANOVA $(n=24)$ showed a significant main effect of choice condition $[F(1,23)=5.95$, $\left.p<.05, \eta_{p}^{2}=.21\right]$, but all further main effects and interactions were nonsignificant [outcome, $F(1,23)=$ 1.67; chances of winning, $F(2,46)=1.77$; Choice Condition $\mathrm{x}$ Outcome, $F(1,23)=2.83$; Choice Condition $\mathrm{x}$ Chances of Winning, $F(1.4,31.2)=1.31$; Outcome $\mathrm{x}$ Chances of Winning, $F(2,46)=1.50$; Choice Condition $\mathrm{x}$ Outcome $\mathrm{x}$ Chances of Winning, $F(1.4,32.6)=1.22]$.

HR deceleration during feedback was affected by active choice and by the chances of winning. A 3 (chances of winning) $\mathrm{x} 2$ (choice condition) $\mathrm{x} 2$ (outcome) ANOVA $(n=28)$ found a significant main effect of choice condition $\left[F(1,27)=5.03, p<.05, \eta_{p}^{2}=.16\right]$, with stronger HR decelerations on no-choice than on activechoice trials $(p<.05)$, and a significant Choice Condition $\mathrm{x}$ Chances of Winning interaction $[F(2,54)=3.81, p<$ $\left..05, \eta_{p}^{2}=.13\right]$. Post-hoc comparisons showed that HR
Fig. 3 Behavioral results. a Decision latencies decreased with increasing chances of winning and were higher for activechoice than for no-choice trials. b For active-choice trials, the average bet that participants chose increased with increasing chances of winning. Error Bars represent standard errors of the means
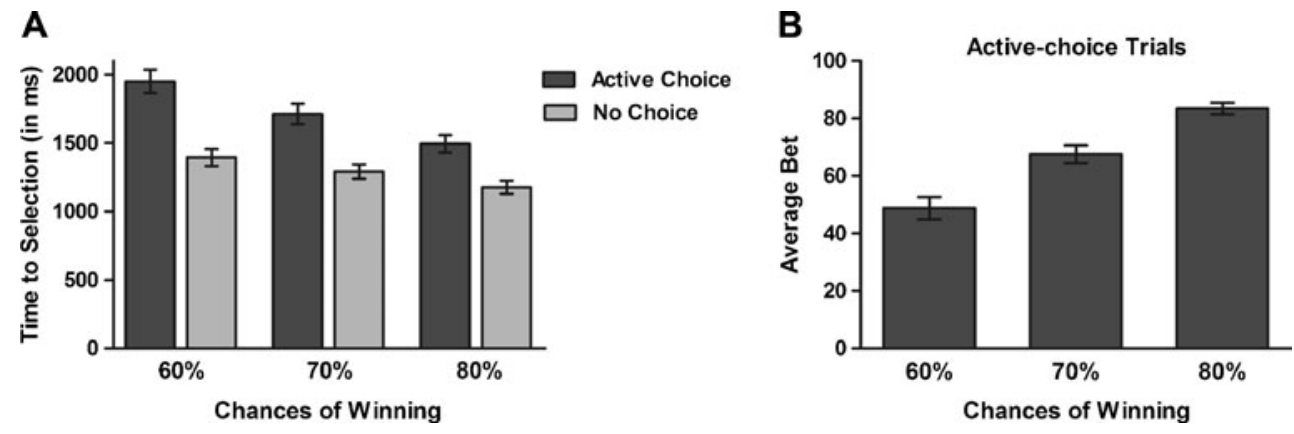


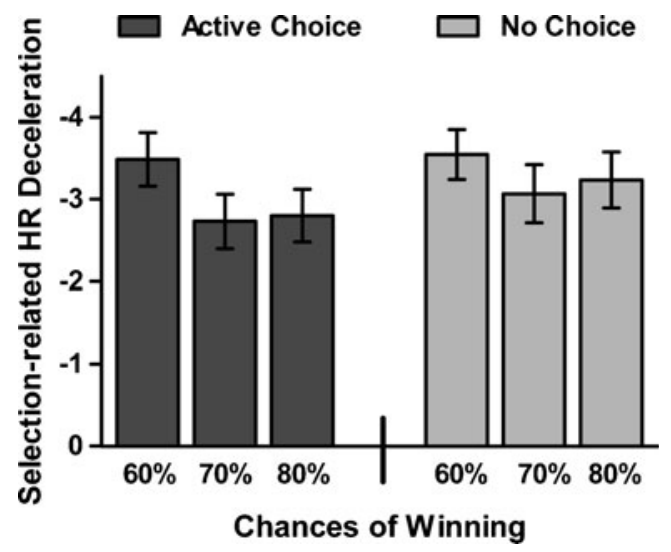

Fig. 4 Selection-related heart rate (HR) decelerations. HR decelerations in active-choice trails were modulated by the chances of winning. In no-choice trials, the HR decelerations did not significantly differ between the different chances of winning. Error bars represent standard errors of the means

decelerations were stronger on no-choice than on activechoice trials when the chances of winning were $60 \%$ or $80 \%$ ( $p$ s $<.01$; see Fig. 5). No further significant main effects or interactions were observed [ratio, $F(2,54)=0.42$; Choice Condition $\mathrm{x}$ Outcome, $F(1,23)=0.26$; Chances of Winning x Outcome, $F(2,54)=0.77$; Choice Condition $\mathrm{x}$ Chances of Winning x Outcome, $F(2,54)=3.19]$.

Feedback-related HR accelerations also showed sensitivity to the choice condition, but not to the chances of winning. In a 3 (chances of winning) $\mathrm{x} 2$ (choice condition) x 2 (outcome) ANOVA $(n=28)$, significant main effects of choice condition $\left[F(1,27)=15.19, p<.001, \eta_{p}^{2}=.36\right]$ and outcome $\left[F(1,27)=11.947, p<.01, \eta_{\mathrm{p}}^{2}=.31\right]$, and a significant Choice Condition $\mathrm{x}$ Chances of Winning interaction $\left[F(2,54)=9.361, p<.001, \eta_{p}^{2}=.26\right]$ were observed, with stronger HR accelerations to feedback in active-choice trials than to feedback in no-choice trials $(p<.01)$ and to wins than to losses in no-choice trials

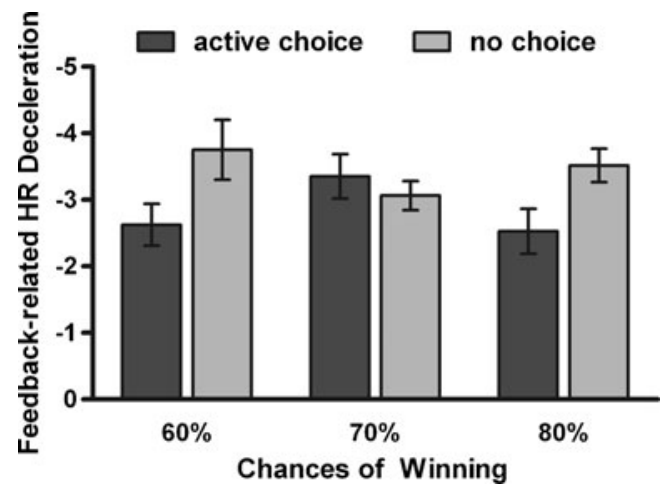

Fig. 5 Feedback-related heart rate (HR) decelerations. HR decelerations differed between active-choice and no-choice trials when the chances of winning were $60 \%$ or $80 \%$. Error bars represent standard errors of the means $(p<.001$; see Fig. 6). No further significant main effects or interactions were found [chances of winning, $F(2,54)=$ 0.31; Choice Condition x Outcome, $F(1,27)=0.01$; Outcome $\mathrm{x}$ Chances of Winning, $F(2,54)=0.54$; Choice Condition $\mathrm{x}$ Outcome $\mathrm{x}$ Chances of Winning, $F(2,54)=0.84]$.

Thus, in accordance with Hypothesis 1A, selectionrelated EDA and HR decelerations were influenced by the requirement for active choice. Contrary to our expectations, however, selection-related HR accelerations were not affected by the choice condition. Similarly, our results confirm Hypothesis 1B: Feedback-related psychophysiological responses (EDA, HR deceleration, and HR acceleration) to the presentation of outcomes were affected by whether or not a participant had made an active choice. Our results were also in line with Hypotheses 2 and 3: The chances of winning did modulate HR decelerations during the selection of explicitly presented risky options and during the feedback period.

\section{Effects of bet size}

\section{Selection-related psychophysiological responses}

The size of the bet modulated EDA during selection. A 2 (bet) $\mathrm{x} 2$ (choice condition) repeated measures ANOVA ( $n$ $=22$, given that some participants selected exclusively from the highest bet) revealed a marginally significant main effect of bet $\left[F(1,21)=3.82, p=.06, \eta_{p}^{2}=.15\right]$, with greater EDA during selection of the higher bets. There was no significant effect of choice condition in this analysis $[F$ $(1,21)=2.82]$, nor a significant Choice Condition $\mathrm{x}$ Bet interaction $[F(1,21)=1.30$; see Fig. 7].

HR decelerations during selection were not sensitive to the size of bets. In contrast, a 3 (bet) $\mathrm{x} 2$ (choice condition) ANOVA $(n=25)$ found no significant main effects and no

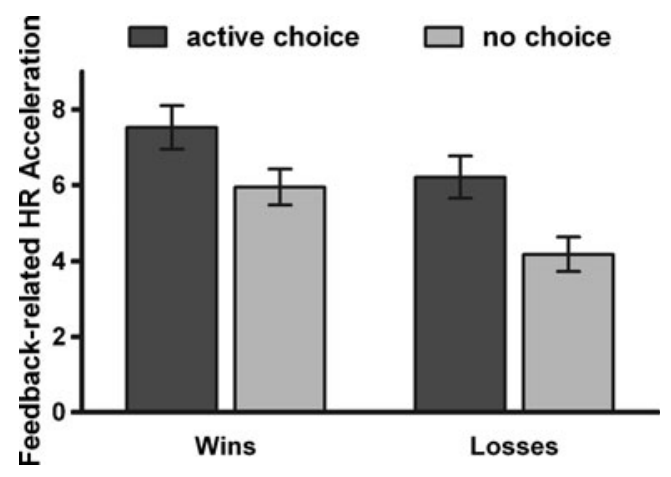

Fig. 6 Feedback-related heart rate (HR) accelerations. Win- and lossrelated HR accelerations were stronger on active-choice than on nochoice trials. Error bars represent standard errors of the means 


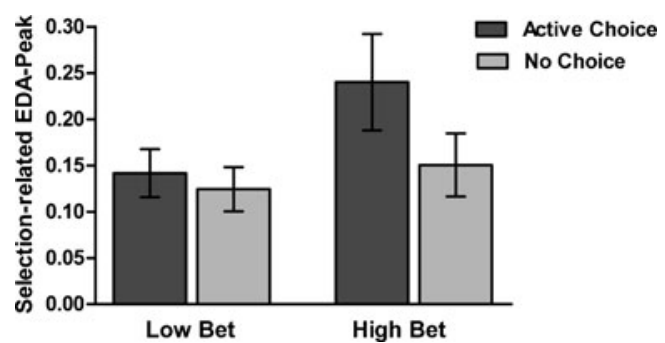

Fig. 7 Selection-related electrodermal activity (EDA) peaks. EDA was higher during the selection of high bets than during selection of low bets. Low bet 10 or 50 points, high bet 90 points. Error bars represent standard errors of the means

significant interaction [choice condition, $F(1,24)=0.46$; bet, $F(1,24)=0.16$; Choice Condition $\times$ Bet, $F(1,24)=0.47]$.

Equally, selection-related HR accelerations were not affected by the size of bets. A 3 (bet) $\times 2$ (choice condition) ANOVA revealed no significant main effects [bet, $F(1,24)=$ 0.19 ; choice condition, $F(1,24)=0.86]$ and no significant Choice Condition $\mathrm{x}$ Bet interaction $[F(1,24)=3.04]$.

Feedback-related psychophysiological responses

As well as showing sensitivity to active choice, feedbackrelated EDA was also modulated by bet size, and these effects depended on outcome valences. A 2 (choice condition) $\times 2$ (outcome) $\times 2$ (bet) ANOVA $(n=20)$ revealed significant main effects of choice condition $[F(1$, $\left.19)=7.26, p<.05, \eta_{p}^{2}=.28\right]$ and bet $[F(1,19)=4.62, p<$ $\left..05, \eta_{p}^{2}=.20\right]$, along with a significant Choice Condition $\mathrm{x}$ Outcome interaction $\left[F(1,19)=4.61, p<.05, \eta_{p}^{2}=.20\right]$, as well as a Bet x Outcome interaction that approached statistical significance $[F(1,19)=3.37, p=.08$, $\left.\eta_{p}^{2}=.15\right]$. EDA responses to low and high losses were stronger in active-choice trials than in no-choice trials $(p s<.05)$. On active-choice trials, EDA was stronger in response to high than to low losses ( $p<.05$; see Fig. $8 \mathrm{~b}$ ). On win trials, however, no significant differences were observed between active-choice and no-choice trials, or between high wins and low wins ( $p$ s $>.05$; see Fig. $8 \mathrm{a})$. In active-choice trials, loss-related EDA was marginally higher than win-related EDA $(p=.07)$, but no differences were found between win-related and loss-related EDA in no-choice trials $(p=.65)$.

Bet size did not modulate the feedback-related HR deceleration. A 2 (bet) $\times 2$ (choice condition) $\times 2$ (outcome) ANOVA $(n=23)$ revealed only a marginally significant effect of choice condition $[F(1,22)=4.02, p=.06$, $\left.\eta_{p}^{2}=.15\right]$. All further main effects and interactions were nonsignificant [outcome, $F(1,22)=1.51$; bet, $F(1,22)=$ 1.16; Choice Condition x Outcome, $F(1,22)=0.61$; Choice Condition $\mathrm{x}$ Bet, $F(1,22)=0.19$; Outcome $\mathrm{x}$ Bet, $F(1,22)=$ 0.34; Choice Condition x Outcome x Bet, $F(1,22)=0.17]$.

Feedback-related HR accelerations also did not vary with the size of bets. A 2 (choice condition) $\mathrm{x} 2$ (outcome) x 2 (bet) ANOVA $(n=23)$ confirmed significant main effects of choice condition $[F(1,22)=12.17, p<.01$, $\left.\eta_{p}^{2}=.36\right]$ and outcome $[F(1,22)=11.52, p<.01$, $\left.\eta_{p}^{2}=.34\right]$ but showed no significant main effect of bet $[F$ $(1,22)=0.22]$ and no significant interactions [Choice Condition $\mathrm{x}$ Outcome, $F(1,22)=0.01$; Choice Condition $\mathrm{x}$ Bet, $F(1,22)=0.13$; Outcome x Bet, $F(1,22)=0.38$; Choice Condition x Outcome x Bet, $F(1,22)=0.01]$.

In conclusion, our findings partially confirm Hypotheses 4 and 5: EDA was sensitive to the size of bets during the selection as well as during the feedback period. Contrary to our expectations, however, selection- and feedback-related HR accelerations were not affected by the bet size. Our results also confirmed Hypothesis 6: Feedback-related EDA and HR accelerations were modulated by the valence of outcomes.

\section{Correlations with trait personality}

Exploratory analysis of the questionnaire data revealed several trait predictors of behavioral responses on the task.

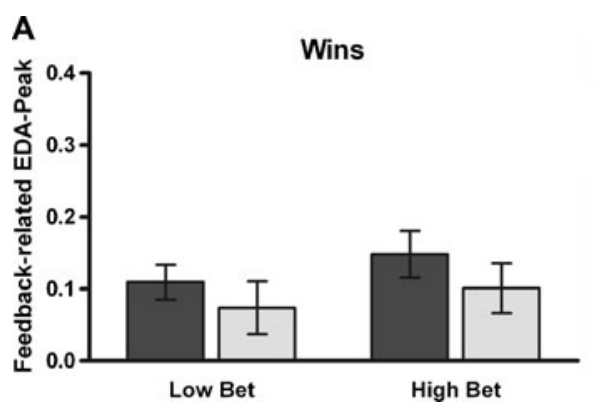

Fig. 8 Feedback-related electrodermal activity (EDA) peaks. Although EDA in response to wins was not significantly affected by the choice condition or by the size of bets (a), loss-related EDA was higher in active-choice than in no-choice trials and was stronger for

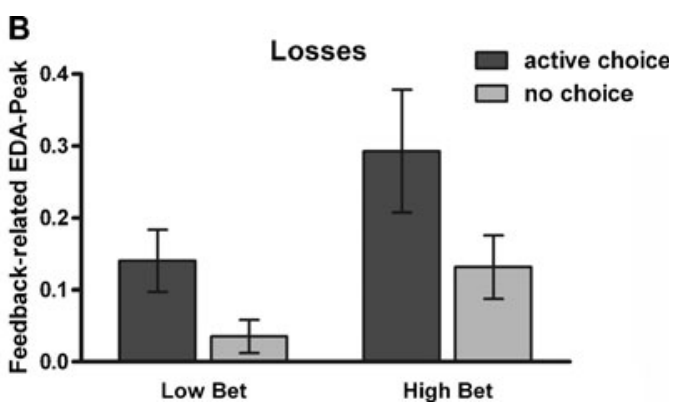

high losses than for low losses in active-choice trials (b). Low bet 10 or 50 points, High bet 90 points. Error bars represent standard errors of the means 
The average bet on active-choice trials was correlated positively with financial risk-taking on the DOSPERT (Spearman's rho $=.39, \mathrm{CI}=.03$ to .66 ) and negatively with financial risk-perception (Spearman's rho $=-.50$, $\mathrm{CI}=-.73$ to -.17 ). Risk adjustment was positively correlated with inhibition (BIS/BAS; Spearman's rho $=.38$, $\mathrm{CI}=.02$ to .65 ) and with financial risk-perception (DOSPERT; Spearman's rho $=.49, \mathrm{CI}=.16$ to .72 ; see Table 1).

On selection-related EDA, the increase on activechoice trials relative to no-choice trials was correlated positively with sensation seeking (SSS; Spearman's rho = $.46, \mathrm{CI}=.07$ to .73 ) and with behavioral activation (BAS; Spearman's rho $=.62, \mathrm{CI}=.28$ to .82 ). The increase in selection-related EDA on high versus low bets was also correlated positively with sensation seeking (Spearman's rho $=.49, \mathrm{CI}=.09$ to .76 ; see Table 2). Thus, participants with higher levels of sensation seeking and behavioral activation showed greater EDA during active choice and during choice of high bets.

With HR, there were no trait correlations against selection-related activity. On feedback-related HR, the difference in HR accelerations to wins versus losses was correlated positively with Barratt impulsivity (Spearman's rho $=.38, \mathrm{CI}=.01$ to .66 ). No correlations between feedback-related EDA and personality were observed.

\section{Discussion}

In this study, we examined psychophysiological arousal during healthy participants' performance of a novel gambling task that assesses decision-making under explicit risk, rather than decision-making in a learning context (i.e., under ambiguity), which has widely been explored in previous studies using the Iowa Gambling Task. We assessed how betting behavior and psychophysiological arousal were affected by (a) the requirement to make an active choice, (b) the magnitude of potential wins/losses, and (c) the chances of winning. Behavioral results showed sensitivity to the choice requirement and to the chances of winning. Measurements of psychophysiological arousal were sensitive to all three factors (summarized in Table 3): First, psychophysiological responses during selection and feedback were more pronounced on trials in which an active choice of bet was required, as compared to the fixedbet trials. Second, selection-related EDA and loss-related EDA responses were potentiated on trials in which a larger bet was staked. Third, HR deceleration during selection was sensitive to the chances of winning, with stronger responses at the greatest level of choice uncertainty.

\section{Requirement for active choice}

Our results highlight the profound importance of active choice: Psychophysiological arousal during the selection of a risky option and during feedback was intensified by the requirement for active choice. These results are in accordance with previous research showing that the emotional and cognitive responses in reward tasks are influenced by choice and motor response requirements. Two previous imaging studies (Coricelli et al., 2005; Rao et al., 2008)

Table 1 Personality and behavioral responses

\begin{tabular}{|c|c|c|c|c|c|c|c|c|}
\hline & & $\begin{array}{l}\text { Financial Risk- } \\
\text { Perception }\end{array}$ & $\begin{array}{l}\text { Financial } \\
\text { Risk-Taking }\end{array}$ & $\begin{array}{l}\text { Sensation } \\
\text { Seeking }\end{array}$ & BAS & BIS & Barratt & $\begin{array}{l}\text { Risk } \\
\text { Adjustment }\end{array}$ \\
\hline \multirow[t]{2}{*}{ Average Bet } & $r_{s}$ & -.50 & .39 & .00 & -.15 & -.34 & .21 & -.77 \\
\hline & $\mathrm{CI}$ & -.73 to -.17 & .03 to .66 & -.36 to .36 & -.48 to .22 & -.63 to .03 & .18 to .54 & -.89 to -.57 \\
\hline Risk & $r_{\mathrm{s}}$ & .49 & -.34 & .11 & -.05 & .38 & -.07 & \\
\hline Adjustment & $\mathrm{CI}$ & .16 to .72 & -.63 to .02 & -.26 to .45 & -.41 to .32 & .02 to .65 & -.43 to .31 & \\
\hline \multirow[t]{2}{*}{ Barratt } & $r_{\mathrm{s}}$ & -.23 & .35 & .63 & .13 & -.07 & & \\
\hline & $\mathrm{CI}$ & -.56 to .16 & -.03 to .64 & .34 to .81 & -.26 to .52 & -.43 to .31 & & \\
\hline \multirow{2}{*}{$\begin{array}{l}\text { Behavioral } \\
\text { Inhibition (BIS) }\end{array}$} & $\mathrm{r}_{\mathrm{s}}$ & .19 & -.00 & .08 & -.07 & & & \\
\hline & $\mathrm{CI}$ & -.19 to .52 & -.36 to .36 & -.29 to .43 & -.43 to .31 & & & \\
\hline \multirow{2}{*}{$\begin{array}{l}\text { Behavioral } \\
\text { Activation (BAS) }\end{array}$} & $\mathrm{r}_{\mathrm{s}}$ & .00 & -.21 & .37 & & & & \\
\hline & $\mathrm{CI}$ & -.36 to .36 & -.53 to .17 & .00 to .65 & & & & \\
\hline \multirow[t]{2}{*}{ Sensation Seeking } & $\mathrm{r}_{\mathrm{s}}$ & -.06 & .20 & & & & & \\
\hline & $\mathrm{CI}$ & -.41 to .31 & -.18 to .52 & & & & & \\
\hline Financial & $\mathrm{r}_{\mathrm{s}}$ & -.45 & & & & & & \\
\hline Risk-Taking & $\mathrm{CI}$ & .11 to .70 & & & & & & \\
\hline
\end{tabular}

$r_{s}$ Spearman's rho, $C I$ 95\% confidence interval. CIs that do not cross zero are indicated in bold type 
Table 2 Personality and selection-related EDA response

\begin{tabular}{|c|c|c|c|c|c|c|c|c|}
\hline & & $\begin{array}{l}\text { Financial Risk- } \\
\text { Perception }\end{array}$ & $\begin{array}{l}\text { Financial } \\
\text { Risk-Taking }\end{array}$ & $\begin{array}{l}\text { Sensation } \\
\text { Seeking }\end{array}$ & BAS & BIS & Barratt & $\begin{array}{l}\text { EDA High } \\
\text { Bet - Low Bet }\end{array}$ \\
\hline $\begin{array}{l}\text { EDA Active } \\
\text { Choice - No Choice }\end{array}$ & $\begin{array}{l}\mathrm{r}_{\mathrm{s}} \\
\mathrm{CI}\end{array}$ & $\begin{array}{l}.11 \\
-.31 \text { to } .49\end{array}$ & $\begin{array}{l}-.09 \\
-.48 \text { to } .32\end{array}$ & $\begin{array}{l}.46 \\
.07 \text { to } .73\end{array}$ & $\begin{array}{l}.62 \\
.28 \text { to } .82\end{array}$ & $\begin{array}{l}-.18 \\
-.55 \text { to } .26\end{array}$ & $\begin{array}{l}.22 \\
-.22 \text { to } .59\end{array}$ & $\begin{array}{l}.65 \\
.31 \text { to } .76\end{array}$ \\
\hline $\begin{array}{l}\text { EDA High } \\
\text { Bet - Low Bet }\end{array}$ & $\begin{array}{l}\mathrm{r}_{\mathrm{s}} \\
\mathrm{CI}\end{array}$ & $\begin{array}{l}.08 \\
-.35 \text { to } .53\end{array}$ & $\begin{array}{l}-.19 \\
-.57 \text { to } .25\end{array}$ & $\begin{array}{l}.49 \\
.09 \text { to } .76\end{array}$ & $\begin{array}{l}.39 \\
-.05 \text { to } .70\end{array}$ & $\begin{array}{l}-.16 \\
-.55 \text { to } .29\end{array}$ & $\begin{array}{l}.38 \\
-.07 \text { to } .70\end{array}$ & \\
\hline Barratt & $\begin{array}{l}\mathrm{r}_{\mathrm{s}} \\
\mathrm{CI}\end{array}$ & $\begin{array}{l}-.31 \\
-.65 \text { to } .13\end{array}$ & $\begin{array}{l}.37 \\
-.06 \text { to } 67\end{array}$ & $\begin{array}{l}.68 \\
.36 \text { to } .86\end{array}$ & $\begin{array}{l}.32 \\
-.65 \text { to } .12\end{array}$ & $\begin{array}{l}-.09 \\
-.49 \text { to } .35\end{array}$ & & \\
\hline $\begin{array}{l}\text { Behavioral } \\
\text { Inhibition (BIS) }\end{array}$ & $\begin{array}{l}\mathrm{r}_{\mathrm{s}} \\
\mathrm{CI}\end{array}$ & $\begin{array}{l}.32 \\
-.11 \text { to } .65\end{array}$ & $\begin{array}{l}.02 \\
-.39 \text { to } .43\end{array}$ & $\begin{array}{l}-.07 \\
-.47 \text { to } .35\end{array}$ & $\begin{array}{l}-.27 \\
-.61 \text { to } .16\end{array}$ & & & \\
\hline $\begin{array}{l}\text { Behavioral } \\
\text { Activation (BAS) }\end{array}$ & $\begin{array}{l}\mathrm{r}_{\mathrm{s}} \\
\mathrm{CI}\end{array}$ & $\begin{array}{l}-.09 \\
-.46 \text { to } .35\end{array}$ & $\begin{array}{l}-.11 \\
-.49 \text { to } .31\end{array}$ & $\begin{array}{l}.39 \\
-.03 \text { to } .69\end{array}$ & & & & \\
\hline Sensation Seeking & $\begin{array}{l}\mathrm{r}_{\mathrm{s}} \\
\mathrm{CI}\end{array}$ & $\begin{array}{l}-.04 \\
.-.44 \text { to } .36\end{array}$ & $\begin{array}{l}.21 \\
-.22 \text { to } 57\end{array}$ & & & & & \\
\hline $\begin{array}{l}\text { Financial } \\
\text { Risk-Taking }\end{array}$ & $\begin{array}{l}\mathrm{r}_{\mathrm{s}} \\
\mathrm{CI}\end{array}$ & $\begin{array}{l}-.36 \\
-.66 \text { to } .05\end{array}$ & & & & & & \\
\hline
\end{tabular}

$r_{s}$ Spearman's rho, $C I 95 \%$ confidence interval. CIs that do not cross zero are indicated in bold type

showed that neural activation in the reward system during selection and in response to feedback was modulated by the choice condition (active and voluntary vs. passive and computer-controlled). We observed that feedback-related EDA differed between wins and losses only in activechoice trials. Consistent with the imaging results of Rao et al., (2008) we furthermore showed that active choice did not affect win-related EDA but enhanced loss-related EDA. Although our results clearly highlight the strong impact of active choice upon psychophysiological arousal during decision-making, certain effects nonetheless also carried over into the no-choice condition. On no-choice trials, reaction times were affected by the chances of winning, and feedback-related HR acceleration differed between wins and losses.

\section{Bet size}

EDA during the selection of a risky option, and in response to losses, increased with the bet size. This result extends previous work with the Iowa Gambling Task, which has shown that increased psychophysiological arousal can serve as a somatic signal and can promote (Bechara, Damasio, \& Damasio, 2000; Damasio, Bechara, \& Damasio, 2002; Tomb et al., 2002) or inhibit (Crone et al., 2004; Damasio, 1994) risky choice, depending on the context. In our task, the expected values were uniformly positive, and the optimal strategy was therefore to bet high. Importantly, in contrast to the Iowa Gambling Task, the magnitude of potential wins and losses was explicitly present in our task, and therefore no learning of the reward contingencies was
Table 3 Sensitivity of selection- and feedbackrelated physiological measurements for active-choice requirement, chances of winning, and bet size

\begin{tabular}{lccc}
\hline & EDA & HR Deceleration & HR Acceleration \\
\hline Selection-Related Psychophysiological Responses & & $\checkmark$ & $\boldsymbol{x}$ \\
Active choice & $\boldsymbol{x}$ & $\checkmark$ & $\boldsymbol{x}$ \\
Chances of winning & $\checkmark$ & $\boldsymbol{x}$ & $\boldsymbol{x}$ \\
Bet size & & $\checkmark$ & $\checkmark$ \\
Win-Related Psychophysiological Responses & $\boldsymbol{x}$ & $\checkmark$ & $\boldsymbol{x}$ \\
Active choice & $\boldsymbol{x}$ & $\boldsymbol{x}$ & $\boldsymbol{x}$ \\
Chances of winning & $\boldsymbol{x}$ & & \\
Bet size & $\checkmark$ & $\checkmark$ & $\checkmark$ \\
Loss-Related Psychophysiological Responses & $\boldsymbol{x}$ & $\boldsymbol{x}$ & $\boldsymbol{x}$ \\
Active choice & $\checkmark$ & $\boldsymbol{x}$ \\
Chances of winning & & \\
Bet size &
\end{tabular}


needed. To the best of our knowledge, this is the first demonstration that psychophysiological arousal during decision-making covaries with the bet amount in a nonlearning environment. Our results are also consistent with economic studies showing that the magnitude of potential wins/losses influences the valuation of risky gambles (Bossaerts \& Plott, 2004; Holt \& Laury, 2002; Lichtenstein \& Slovic, 1971; Slovic et al., 2007; Slovic \& Lichtenstein, 1968), and they extend this finding to EDA sensitivity.

\section{Chances of winning}

In addition to the bet size, psychophysiological responses were also sensitive to the chances of winning: Selectionand feedback-related HR decelerations were modulated by the chances of winning - that is to say, by choice uncertainty. Previous research (e.g., Bradley, 2000; Crone et al., 2004; Hodes et al., 1985; Somsen, Van der Molen, \& Orlebeke, 1983) has suggested that HR deceleration reflects the extent to which attention is allocated to potentially aversive stimuli, is stronger in situations in which the frequency of potential punishment is high, and reacts to expectancy violations. Interestingly, in our study EDA and HR showed differential sensitivities to the three aspects of the decision that we manipulated in our task. The observation that different physiological responses can react differently to the same arousing situation can be traced back to Lacey (1967; see also defense cascade: Lang, 1995; Lang, Bradley, \& Cuthbert, 1997) and can be explained by distinct associations with the parasympathetic and sympathetic systems. HR decelerations reflect parasympathetic activity, are sensitive to valence, and serve to increase attention and orienting. HR acceleration and EDA, on the other hand, are controlled by the sympathetic system and reflect the intensity of emotions, rather than their valence (see Bradley \& Lang, 2007, for a review). Our results fit into this wider framework by showing that during decisionmaking, HR decelerations are more pronounced in situations with higher choice uncertainty, whereas EDA and HR accelerations are enhanced by the requirement to make an active choice and by higher bet amounts - factors that are thought to intensify emotional arousal during decisionmaking. In addition, our results compare to the findings of neuroimaging studies of decision-making, which have shown that in the brain, the probability and the magnitude of potential rewards are also encoded by two distinct neural signals (Critchley et al., 2001; Huettel et al., 2005; Huettel et al., 2006; Preuschoff et al., 2006; Preuschoff et al., 2008; Smith et al., 2009; Tobler et al., 2009; Xue et al., 2009). Importantly, several of the brain regions known to encode the riskiness of decisions are also involved in the cortical control and mapping of electrodermal activity and cardiac responses, notably the anterior cingulate cortex, the ventromedial prefrontal cortex, and the insula (Craig, 2009, 2010; Craig et al., 2000; Critchley, 2005; Critchley et al., 2000, 2001, 2003; Gianaros et al., 2004; Ohira et al., 2010; Thayer \& Lane, 2009).

\section{Individual differences}

A further goal of this study was to investigate whether personality traits are linked to a person's betting behavior and psychophysiological reactivity during decision-making. Three main results were obtained in an exploratory analysis. First, betting behavior was correlated with selfreported financial risk-taking attitudes and with differences in trait behavioral inhibition. Second, individual differences in sensation seeking and behavioral activation were correlated with selection-related EDA. Participants with higher scores on the SSS and BIS/BAS scales showed stronger reactivity related to active choice and high bet size during selection. Third, we observed a positive correlation between impulsivity and the differential responses to wins as compared to losses. We believe that ours is the first study to link these impulsivity-related traits with psychophysiological indices during decision-making. Our results complement previous studies that have linked individual differences in impulsive traits with laboratory risk-taking behavior (Franken et al., 2008; Sweitzer et al., 2008), with neural activity during reward anticipation (Hahn et al., 2009), with neural activation of the reward system in response to monetary outcomes (Bjork et al., 2008), and with midbrain dopamine autoreceptor availability (Buckholtz et al., 2010). Our findings demonstrate that differences in impulsive traits constitute important sources of heterogeneity in risk-taking behavior, for consideration in future research. In addition, this constellation of traits have been identified as risk factors for forms of addiction, including drug abuse and problem gambling. Pathological gamblers tend to score higher than healthy controls on novelty seeking and impulsivity (Forbush et al., 2008; Kim \& Grant, 2001; Lawrence, Luty, Bogdan, Sahakian, \& Clark, 2009; Nordin \& Nylander, 2007; Verdejo-García et al., 2008), and these traits in adolescence prospectively predict later drug use and gambling problems (Slutske, Caspi, Moffitt, \& Poulton, 2005; Vitaro, Arseneault, \& Tremblay, 1999). In light of the key role that psychophysiological arousal is likely to play in the maintenance of gambling behavior (see Goudriaan, Oosterlaan, de Beurs, \& Van den Brink, 2004, for a review), it could be speculated from our data that individuals with higher levels of trait novelty seeking and behavioral activation might experience stronger risk-induced psychophysiological arousal and might be at increased risk of developing disordered gambling. At 
the same time, given that HR and EDA were sensitive to different aspects of risky decisions, our results caution against a simple treatment of psychophysiological arousal during gambling as a unitary construct.

There are limitations to the present study. Primarily, we monitored psychophysiological activity in a correlational design, and though we were able to associate certain aspects of decision-making with bodily signals, we could not ascertain the causal significance of these signals in the decision-making process (see Dunn, Dalgleish, \& Lawrence 2006; Moors, 2009). Further work will be required in order to look at the effects of autonomic manipulations (e.g., epinephrine injection) or autonomic pathologies on subtle aspects of decision-making performance. The second caveat pertains to our task design. On active-choice trials, participants were free to select their bets, and a minority of participants did not distribute their bets over the available range. We were thus forced to collapse across the low and medium bets, therefore comparing only two levels of bet size. In addition, our analyses of bet size and chances of winning included slightly differing numbers of participants. Third, the gambles in our design had a positive expected value, such that the chances of winning were uniformly higher than the chances of losing, and wins were more frequent outcomes than losses. It is conceivable that both the selection- and feedback-related responses could differ in a decision environment with a negative expected value and a higher frequency of losses. Future research should investigate the distinct influence of positive versus negative expected values upon psychophysiological arousal during explicit risky decision-making.

In conclusion, the results of this study underline the role of emotional processes in risk-sensitive decision-making. Psychophysiological measurements during selection of a risky option and in response to wins and losses are intensified by active choice and modulated by the explicit risk associated with decisions (the chances of winning and the bet size). Additionally, our results show that different psychophysiological markers (HR decelerations and EDA) signal different aspects of the riskiness of a decision. Finally, this research has revealed that differences in personality traits, including behavioral activation and sensation seeking, as well as everyday risk-taking propensities (assessed using the DOSPERT), help explain individual differences in physiological arousal during risky decision-making and in actual betting behavior.

Author Note This work was completed within the Behavioral and Clinical Neuroscience Institute, supported by a consortium award from the MRC and Wellcome Trust (director: T. W. Robbins). B.S. was supported by an MRC postgraduate studentship, and L.C. received funding from the British Academy (Grant SG 52374). We thank Barney Dunn, Graeme Fairchild, and Mike Aitken for discussion and feedback on an earlier draft of the manuscript.
Open Access This article is distributed under the terms of the Creative Commons Attribution Noncommercial License which permits any noncommercial use, distribution, and reproduction in any medium, provided the original author(s) and source are credited.

\section{References}

Barrett, L. F., \& Lindquist, K. A. (2008). The embodiment of emotion. In G. R. Semin \& E. R. Smith (Eds.), Embodied grounding: Social, cognitive, affective, and neuroscientific approaches (pp. 237-264). New York: Cambridge University Press.

Bechara, A., Damasio, H., \& Damasio, A. R. (2000). Emotion, decision making and the orbitofrontal cortex. Cerebral Cortex, 10, 295-307.

Bechara, A., Damasio, H., Damasio, A. R., \& Lee, G. P. (1999). Different contributions of the human amygdala and ventromedial prefrontal cortex to decision-making. The Journal of Neuroscience, 19, 5473-5481.

Bechara, A., Damasio, H., Tranel, D., \& Damasio, A. R. (1997). Deciding advantageously before knowing the advantageous strategy. Science, 275, 1293-1295. doi:10.1126/science.275.5304.1293.

Bjork, J. M., Smith, A. R., \& Hommer, D. W. (2008). Striatal sensitivity to reward deliveries and omissions in substance dependent patients. Neuroimage, 42, 1609-1621.

Blais, A.-R., \& Weber, E. U. (2006). A Domain-Specific Risk-Taking (DOSPERT) Scale for adult populations. Judgment and Decision Making, 1, 33-47.

Bossaerts, P., \& Plott, C. (2004). Basic principles of asset pricing theory: Evidence from large-scale experimental financial markets. Review of Finance, 8, 135-169. doi:10.1023/B: EUFI.0000035190.24818.e5.

Bradley, M. M. (2000). Emotion and motivation. In J. T. Cacioppo, L. G. Tassinary, \& G. G. Berntson (Eds.), Handbook of psychophysiology (2nd ed., pp. 602-642). New York: Cambridge University Press.

Bradley, M. M. (2009). Natural selective attention: Orienting and emotion. Psychophysiology, 46, 1-11. doi:10.1111/j.14698986.2008.00702.x.

Bradley, M. M., Codispoti, M., Cuthbert, B. N., \& Lang, P. J. (2001). Emotion and motivation I: Defensive and appetitive reactions in picture processing. Emotion, 1, 276-298. doi:10.1037/15283542.1.3.276.

Bradley, M. M., \& Lang, P. J. (2007). Emotion and motivation. In J. T. Cacioppo, L. G. Tassinary, \& G. G. Berntson (Eds.), Handbook of psychophysiology (3rd ed., pp. 581-607). New York: Cambridge University Press.

Brand, M., Labudda, K., \& Markowitsch, H. J. (2006). Neuropsychological correlates of decision-making in ambiguous and risky situations. Neural Networks, 19, 1266-1276.

Buckholtz, J. W., Treadway, M. T., Cowan, R. L., Woodward, N. D., Li, R., Ansari, M. S., et al. (2010). Dopaminergic network differences in human impulsivity. Science, 329, 532. doi:10.1126/ science. 1185778 .

Carter, S., \& Pasqualini, M. C. S. (2004). Stronger autonomic response accompanies better learning: A test of Damasio's somatic marker hypothesis. Cognition and Emotion, 18, 901-911.

Carver, C. S., \& White, T. L. (1994). Behavioral inhibition, behavioral activation, and affective responses to impending reward and punishment: The BIS/BAS Scales. Journal of Personality and Social Psychology, 67, 319-333. doi:10.1037/0022-3514.67.2.319.

Clark, L., Lawrence, A. J., Astley-Jones, F., \& Gray, N. (2009). Gambling near-misses enhance motivation to gamble and recruit win-related brain circuitry. Neuron, 61, 481-490. 
Cook, E. W., Hawk, L. W., Davis, T. L., \& Stevenson, V. E. (1991). Affective individual differences and startle reflex modulation. Journal of Abnormal Psychology, 100, 5-13.

Coricelli, G., Critchley, H. D., Joffily, M., O’Doherty, J. P., Sirigu, A., \& Dolan, R. J. (2005). Regret and its avoidance: a neuroimaging study of choice behavior. Nature Neuroscience, $8,1255-1262$.

Coricelli, G., Dolan, R. J., \& Sirigu, A. (2007). Brain, emotion and decision making: The paradigmatic example of regret. Trends in Cognitive Sciences, 11, 258-265.

Craig, A. D. (2009). How do you feel - now? The anterior insula and human awareness. Nature Reviews. Neuroscience, 10, 59-70.

Craig, A. D. (2010). The sentient self. Brain Structure \& Function, 214, 563-577. doi:10.1007/s00429-010-0248-y.

Craig, A. D., Chen, K., Bandy, D., \& Reiman, E. M. (2000). Thermosensory activation of insular cortex. Nature Neuroscience, 3, 184-190.

Critchley, H. D. (2005). Neural mechanisms of autonomic, affective, and cognitive integration. The Journal of Comparative Neurology, 493, 154-166. doi:10.1002/cne.20749.

Critchley, H. D., Elliott, R., Mathias, C. J., \& Dolan, R. J. (2000). Neural activity relating to generation and representation of galvanic skin conductance responses: A functional magnetic resonance imaging study. The Journal of Neuroscience, 20, 3033-3040.

Critchley, H. D., Mathias, C. J., \& Dolan, R. J. (2001). Neural activity in the human brain relating to uncertainty and arousal during anticipation. Neuron, 29, 537-545.

Critchley, H. D., Mathias, C. J., Josephs, O., O’Doherty, J., Zanini, S., Dewar, B. K., et al. (2003). Human cingulate cortex and autonomic control: Converging neuroimaging and clinical evidence. Brain, 126, 2139-2152. doi:10.1093/brain/awg216.

Crone, E. A., Bunge, S. A., de Klerk, P., \& van der Molen, M. W. (2005). Cardiac concomitants of performance monitoring: Context dependence and individual differences. Cognitive Brain Research, 23, 93-106.

Crone, E. A., Somsen, R. J. M., Van Beek, B., \& Van der Molena, M. W. (2004). Heart rate and skin conductance analysis of antecendents and consequences of decision making. Psychophysiology, 41, 531-540.

Crone, E. A., van der Veen, F. M., van der Molen, M. W., Somsen, R. J. M., van Beek, B., \& Jennings, J. R. (2003). Cardiac concomitants of feedback processing. Biological Psychology, $64,143-156$

Damasio, A. R. (1994). Descartes' error: Emotion, reason and the human brain. New York: Grosset/Putamen.

Damasio, H., Bechara, A., \& Damasio, A. R. (2002). Reply to "Do somatic markers mediate decisions on the gambling task?". Nature Neuroscience, 5, 1104-1104.

Damasio, A. R., Everitt, B. J., \& Bishop, D. (1996). The somatic marker hypothesis and the possible functions of the prefrontal cortex [and discussion]. Philosophical Transactions of the Royal Society B, 351, 1413-1420. doi:10.1098/rstb.1996.0125.

Davis, D., Sundahl, I., \& Lesbo, M. (2000). Illusory personal control as a determinant of bet size and type in casino craps games. Journal of Applied Social Psychology, 30, 1224-1242.

Dawson, M. E., Schell, A. M., \& Filion, D. (2007). The electrodermal system. In J. T. Cacioppo, L. G. Tassinary, \& G. G. Berntson (Eds.), Handbook of psychophysiology (3rd ed., p. 165). New York: Cambridge University Press.

Dixon, M. J., Harrigan, K. A., Sandhu, R., Collins, K., \& Fugelsang, J. A. (2010). Losses disguised as wins in modern multi-line video slot machines. Addiction, 105, 1819-1824. doi:10.1111/j.13600443.2010.03050.x

Dolan, R. J. (2002). Emotion, cognition, and behavior. Science, 298, 1191-1194. doi:10.1126/science. 1076358.
Dunn, B. D., Dalgleish, T., \& Lawrence, A. D. (2006). The somatic marker hypothesis: A critical evaluation. Neuroscience and Biobehavioral Reviews, 30, 239-271.

Forbush, K. T., Shaw, M., Graeber, M. A., Hovick, L., Meyer, V. J., Moser, D. J., et al. (2008). Neuropsychological characteristics and personality traits in pathological gambling. CNS Spectrums, 13, 306-315.

Fowles, D. C., Christie, M. J., Edelberg, R., Grings, W. W., Lykken, D. T., \& Venables, P. H. (1981). Publication recommendations for electrodermal measurements [Editorial material]. Psychophysiology, 18, 232-239.

Franken, I. H. A., van Strien, J. W., Nijs, I., \& Muris, P. (2008). Impulsivity is associated with behavioral decision-making deficits. Psychiatry Research, 158, 155-163.

Gianaros, P. J., Van der Veen, F. M., \& Jennings, J. R. (2004). Regional cerebral blood flow correlates with heart period and high-frequency heart period variability during working-memory tasks: Implications for the cortical and subcortical regulation of cardiac autonomic activity. Psychophysiology, 41, 521-530. doi:10.1111/1469-8986.2004.00179.x.

Goudriaan, A. E., Oosterlaan, J., de Beurs, E., \& Van den Brink, W. (2004). Pathological gambling: A comprehensive review of biobehavioral findings. Neuroscience and Biobehavioral Reviews, 28, 123-141.

Graham, F. K., \& Clifton, R. K. (1966). Heart-rate change as a component of the orienting response. Psychological Bulletin, 65, 305-320.

Guillaume, S., Jollant, F., Jaussent, I., Lawrence, N., Malafosse, A., \& Courtet, P. (2009). Somatic markers and explicit knowledge are both involved in decision-making. Neuropsychologia, 47, 2120-2124.

Hahn, T., Dresler, T., Ehlis, A.-C., Plichta, M. M., Heinzel, S., Polak, T., et al. (2009). Neural response to reward anticipation is modulated by Gray's impulsivity. Neuroimage, 46, 1148-1153.

Hajcak, G., McDonald, N., \& Simons, R. F. (2004). Error-related psychophysiology and negative affect. Brain and Cognition, 56, 189-197.

Henslin, J. M. (1967). Craps and magic. The American Journal of Sociology, 73, 316-330. doi:10.1086/224479.

Hodes, R. L., Cook, E. W., III, \& Lang, P. J. (1985). Individual differences in autonomic response: conditioned association or conditioned fear? Psychophysiology, 22, 545-560.

Holt, C. A., \& Laury, S. K. (2002). Risk aversion and incentive effects. The American Economic Review, 92, 1644-1655.

Huettel, S. A., Song, A. W., \& McCarthy, G. (2005). Decisions under uncertainty: Probabilistic context influences activation of prefrontal and parietal cortices. The Journal of Neuroscience, 25, 3304-3311. doi:10.1523/jneurosci.5070-04.2005.

Huettel, S. A., Stowe, C. J., Gordon, E. M., Warner, B. T., \& Platt, M. L. (2006). Neural signatures of economic preferences for risk and ambiguity. Neuron, 49, 765-775.

Kenning, P., \& Plassmann, H. (2005). NeuroEconomics: An overview from an economic perspective. Brain Research Bulletin, 67, 343-354.

Kim, S. W., \& Grant, J. E. (2001). Personality dimensions in pathological gambling disorder and obsessive-compulsive disorder. Psychiatry Research, 104, 205-212.

Lacey, J. I. (1967). Somatic response patterning and stress: Some revisions of activation theory. In M. H. Appley \& R. Trumbull (Eds.), Psychological stress: Issues in research (pp. 14-38). New York: Appleton-Century-Crofts.

Ladouceur, R., \& Mayrand, M. (1987). The level of involvement and the timing of betting in roulette. Journal of Psychology: Interdisciplinary and Applied, 121, 169-176.

Lang, P. J. (1995). The emotion probe: Studies of motivation and attention. The American Psychologist, 50, 372-385. doi:10.1037/ 0003-066x.50.5.372.

Lang, P. J., Bradley, M. M., \& Cuthbert, M. M. (1997). Motivated attention: Affect, activation and action. In P. J. Lang, R. F. Simons, \& M. T. Balaban (Eds.), Attention and orienting: 
Sensory and motivational processes (pp. 97-136). Mahwah: Erlbaum.

Lang, P. J., \& Davis, M. (2006). Emotion, motivation, and the brain: Reflex foundations in animal and human research. Progress in Brain Research, 156, 3-29.

Langer, E. J. (1975). The illusion of control. Journal of Personality and Social Psychology, 32, 311-328. doi:10.1037/0022-3514.32.2.311.

Lawrence, A., Luty, J., Bogdan, N., Sahakian, B., \& Clark, L. (2009). Impulsivity and response inhibition in alcohol dependence and problem gambling. Psychopharmacology, 207, 163172.

Lee, D. (2006). Neural basis of quasi-rational decision making. Current Opinion in Neurobiology, 16, 191-198.

Liao, P.-C., Uher, R., Lawrence, N., Treasure, J., Schmidt, U., Campbell, I. C., et al. (2009). An examination of decision making in bulimia nervosa. Journal of Clinical and Experimental Neuropsychology, 31, 455-461.

Lichtenstein, S., \& Slovic, P. (1971). Reversals of preference between bids and choices in gambling decisions. Journal of Experimental Psychology, 89, 46-55.

Loewenstein, G. F., Weber, E. U., Hsee, C. K., \& Welch, N. (2001). Risk as feelings. Psychological Bulletin, 127, 267-286.

Miu, A. C., Heilman, R. M., \& Houser, D. (2008). Anxiety impairs decision-making: Psychophysiological evidence from an Iowa Gambling Task. Biological Psychology, 77, 353-358.

Moors, A. (2009). Theories of emotion causation: A review. Cognition and Emotion, 23, 625-662.

Niedenthal, P. M. (2007). Embodying emotion. Science, 316, 1002 1005. doi:10.1126/science. 1136930.

Niedenthal, P. M., Barsalou, L. W., Winkielman, P., Krauth-Gruber, S., \& Ric, F. O. (2005). Embodiment in attitudes, social perception, and emotion. Personality and Social Psychology Review, 9, 184-211.

Nordin, C., \& Nylander, P.-O. (2007). Temperament and character in pathological gambling. Journal of Gambling Studies, 23, 113120.

O’Doherty, J., Dayan, P., Schultz, J., Deichmann, R., Friston, K., \& Dolan, R. J. (2004). Dissociable roles of ventral and dorsal striatum in instrumental conditioning. Science, 304, 452-454. doi:10.1126/science.1094285.

Ohira, H., Ichikawa, N., Nomura, M., Isowa, T., Kimura, K., Kanayama, N., et al. (2010). Brain and autonomic association accompanying stochastic decision-making. Neuroimage, 49, 1024-1037.

Osumi, T., \& Ohira, H. (2009). Cardiac responses predict decisions: An investigation of the relation between orienting response and decisions in the ultimatum game. International Journal of Psychophysiology, 74, 74-79.

Patton, J. H., Stanford, M. S., \& Barratt, E. S. (1995). Factor structure of the Barratt impulsiveness scale. Journal of Clinical Psychology, 51, 768-774.

Platt, M. L., \& Huettel, S. A. (2008). Risky business: the neuroeconomics of decision making under uncertainty. Nature Neuroscience, 11, 398-403.

Preuschoff, K., Bossaerts, P., \& Quartz, S. R. (2006). Neural differentiation of expected reward and risk in human subcortical structures. Neuron, 51, 381-390.

Preuschoff, K., Quartz, S. R., \& Bossaerts, P. (2008). Human insula activation reflects risk prediction errors as well as risk. The Journal of Neuroscience, 28, 2745-2752. doi:10.1523/jneurosci. 4286-07.2008.

Rao, H., Korczykowski, M., Pluta, J., Hoang, A., \& Detre, J. A. (2008). Neural correlates of voluntary and involuntary risk taking in the human brain: An fMRI study of the balloon analog risk task (BART). Neuroimage, 42, 902-910.
Slovic, P., Finucane, M. L., Peters, E., \& MacGregor, D. G. (2007). The affect heuristic. European Journal of Operational Research, 177, 1333-1352.

Slovic, P., \& Lichtenstein, S. (1968). Relative importance of probabilities and payoffs in risk taking. Journal of Experimental Psychology, 78, 1-18.

Slutske, W. S., Caspi, A., Moffitt, T. E., \& Poulton, R. (2005). Personality and problem gambling: A prospective study of a birth cohort of young adults. Archives of General Psychiatry, 62, 769775. doi:10.1001/archpsyc.62.7.769.

Smith, B. W., Mitchell, D. G. V., Hardin, M. G., Jazbec, S., Fridberg, D., Blair, R. J. R., et al. (2009). Neural substrates of reward magnitude, probability, and risk during a wheel of fortune decision-making task. Neuroimage, 44, 600-609.

Somsen, R. J. M., Van der Molen, M. W., Jennings, J. R., \& van Beek, B. (2000). Wisconsin card sorting in adolescents: Analysis of performance, response times and heart rate. Acta Psychologica, 104, 227 257.

Somsen, R. J. M., Van der Molen, M. W., \& Orlebeke, J. F. (1983). Phasic heart rate changes in reaction time, shock avoidance, and unavoidable shock tasks: Are hypothetical generalizations about different S1-S2 tasks justified? Psychophysiology, 20, 88-94.

Starcke, K., Tuschen-Caffier, B., Markowitsch, H.-J., \& Brand, M. (2009). Skin conductance responses during decisions in ambiguous and risky situations in obsessive-compulsive disorder. Cognitive Neuropsychiatry, 14, 199-216.

Sweitzer, M. M., Allen, P. A., \& Kaut, K. P. (2008). Relation of individual differences in impulsivity to nonclinical emotional decision making. Journal of the International Neuropsychological Society, 14, 878-882. doi:10.1017/S1355617708080934.

Tchanturia, K., Liao, P.-C., Uher, R., Lawrence, N., Treasure, J., \& Campbell, I. C. (2007). An investigation of decision making in anorexia nervosa using the Iowa Gambling Task and skin conductance measurements. Journal of the International Neuropsychological Society, 13, 635-641. doi:10.1017/ S1355617707070798.

Thayer, J. F., \& Lane, R. D. (2009). Claude Bernard and the heartbrain connection: Further elaboration of a model of neurovisceral integration. Neuroscience and Biobehavioral Reviews, 33, 81-88.

Tobler, P. N., Christopoulos, G. I., O’Doherty, J. P., Dolan, R. J., \& Schultz, W. (2009). Risk-dependent reward value signal in human prefrontal cortex. Proceedings of the National Academy of Sciences, 106, 7185-7190. doi:10.1073/pnas.0809599106.

Tomb, I., Hauser, M., Deldin, P., \& Caramazza, A. (2002). Do somatic markers mediate decisions on the gambling task? Nature Neuroscience, 5, 1103-1104.

Tricomi, E. M., Delgado, M. R., \& Fiez, J. A. (2004). Modulation of caudate activity by action contingency. Neuron, 41, 281-292.

Van der Veen, F. M., Van der Molen, M. W., Crone, E. A., \& Jennings, J. R. (2004). Phasic heart rate responses to performance feedback in a time production task: effects of information versus valence. Biological Psychology, 65, 147-161.

Verdejo-García, A., Lawrence, A. J., \& Clark, L. (2008). Impulsivity as a vulnerability marker for substance-use disorders: Review of findings from high-risk research, problem gamblers and genetic association studies. Neuroscience and Biobehavioral Reviews, 32, 777-810.

Vitaro, F., Arseneault, L., \& Tremblay, R. E. (1999). Impulsivity predicts problem gambling in low SES adolescent males. Addiction, 94, 565-575. doi:10.1046/j.1360-0443.1999.94456511.x.

Vorhold, V. (2008). The neuronal substrate of risky choice. Annals of the New York Academy of Sciences, 1128, 41-52.

Walton, M. E., Croxson, P. L., Behrens, T. E. J., Kennerley, S. W., \& Rushworth, M. F. S. (2007). Adaptive decision making and value in the anterior cingulate cortex. Neuroimage, 36(Suppl. 2), T142T154. 
Wilkes, B. L., Gonsalvez, C. J., \& Blaszczynski, A. (2010). Capturing SCL and HR changes to win and loss events during gambling on electronic machines. International Journal of Psychophysiology, 78, 265-272.

Xue, G., Lu, Z., Levin, I. P., Weller, J. A., Li, X., \& Bechara, A. (2009). Functional dissociations of risk and reward processing in the medial prefrontal cortex. Cerebral Cortex, 19, 1019-1027. doi:10.1093/cercor/bhn147.
Zink, C. F., Pagnoni, G., Martin-Skurski, M. E., Chappelow, J. C., \& Berns, G. S. (2004). Human striatal responses to monetary reward depend on saliency. Neuron, 42, 509-517.

Zuckerman, M., Eysenck, S. B., \& Eysenck, H. J. (1978). Sensation seeking in England and America: Cross-cultural, age, and sex comparisons. Journal of Consulting and Clinical Psychology, 46, 139-149. doi:10.1037/0022-006x.46.1.139. 